\title{
Impactos ambientais da mineração e da expansão urbana em Minas Gerais, Brasil: o caso de Congonhas - patrimônio cultural da humanidade
}

\author{
Environmental impacts of mining and urban expansion in Minas Gerais, Brazil: case of \\ Congonhas - humanity's cultural heritage
}

\begin{abstract}
Mariza Ferreira da Silva
1 Doutoranda em Geografia - Universidade Federal do Paraná; Geógrafa Bacharel Licenciada e Mestra em Geografia: Tratamento da Informação Espacial - Pontifícia Universidade Católica de Minas Gerais; Pedagoga - Fundação Mineira de Educação e Cultura; Especialista em Educação - Instituto de Educação de Minas Gerais. E-mail: marizzafs@hotmail.com
\end{abstract}

\begin{abstract}
RESUMO: Muitas transformações urbanas têm afetado a cidade de Congonhas e outras cidades da rede de influência de Belo Horizonte, onde tem havido um processo continuado de modernização industrial e um forte desenvolvimento de atividades do setor terciário. As alterações nas paisagens urbanas de Congonhas no perío do atual e o processo de periurbanização e conurbação com os municípios de Conselheiro Lafaiete e Ouro Branco na área de mineração, pertencente ao Quadrilátero Ferrífero e à Bacia do Rio Maranhão, foram fatores determinantes para o início da investigação científica.
\end{abstract}

Palavras-chave: Geociência - Meio Ambiente - Exploração Mineral - Paisagens Urbanas - Conurbação

\begin{abstract}
Many urban changes have affected the city of Congonhas and other cities in the network of influence of Belo Horizonte, where there has been a continuous process of modernization and a strong industrial development activity in the tertiary sector. Changes in Congonhas urban landscapes in the current period and the process of periurbanization and conurbation with the cities of Conselheiro Lafaiete and Ouro Branco in the area, belonging to the Quadrangle and the catchment were determining factors for beginning of the research.
\end{abstract}

Keywords: Geoscience - Environment - Mineral Exploration - Urban Landscapes - Conurbation

Sumário: 1. Introdução - 2. Caracterização da Cidade - Ambiente Histórico-Cultural Construído, Percebido, Vivido; 2.1. O Espaço Regional de Expansão Urbana de Congonhas: a Bacia do Rio Maranhão; 3. M etodologia de Análise Científica e Geocartografia Aplicada; 4. Problemas Ambientais da M ineração e da Expansão Urbana - Assentamentos Urbanos Irregulares e Ocupação das Encostas Como Fatores de Risco; 4.1. Desafios Impostos Pela M ineração Em Perímetro Urbano: Gestão M unicipal Participativa, Desenvolvimento Ambiental Sustentável, Educação Ecológica e Erradicação de Problemas Na Saúde Pública; 5. Zoneamento Morfológico-Funcional da Cidade de Congonhas - Expansão Urbana e Hipótese de Conurbação Com as Cidades Ouro Branco e Conselheiro Lafaiete; 6. Considerações Finais - Referências. 


\section{INTRODUÇÃO}

Analisar o sítio (localização física) e o tecido urbano em expansão (espaço construído = cidade), tomando como referência a posição geográfica de Congonhas na Bacia do Rio Maranhão, localizada na área de abrangência do Quadrilátero Ferrífero é proposta deste artigo, tendo em vista, as alterações ambientais provenientes da urbanização desordenada e da 0corrência de atividades da mineração, de forma exacerbada, consideradas como fatores de risco para a população da cidade de Congonhas - o Patrimônio Cultural da Humanidade - e as cidades de Conselheiro Lafaiete e Ouro Branco, que fazem parte do mesmo contexto histórico-geográfico.

Congonhas vem apresentando características de uma cidade que, até recentemente pequena, ganha impulso e dinamismo. As paisagens geográficas urbanas, atuais, observadas em trabalhos de campo, testemunham o processo de evolução da cidade (antiga e recente), marcada por contrastes. Percebem-se, exatamente, as condições naturais do sítio onde a cidade foi assentada. Apesar do relevo acidentado, a ocupação e os assentamentos ocorreram de forma abrupta desencadeando o fenômeno urbano-industrial recente, com todas as consequências sociais e problemas ambientais advindas desse processo. Na ocupação das vertentes é possível verificar as diferenciações paisagísticas: naturais, humanas e culturais.

A análise do sítio justificou-se, porque a ocupação urbana se expandiu das margens do Rio M aranhão para as encostas, atingindo o topo do M orro M aranhão. E daí para as encostas dos demais morros. 0 sítio da cidade foi um dos fatores determinantes para o povoamento original (às margens do Rio Maranhão) há 300 anos aproximadamente. A condição natural do município atraiu a ocupação original e o início desse povoamento, tornando a região de Congonhas um grande centro de mineração em M inas Gerais com potencial de exportação. Essa condição original do povoamento da região demonstra ser hoje, para Congonhas, fonte de muitos problemas sociais e urbanos. A origem, desses problemas socioambientais, também foi investigada.

A História (evolução do tecido urbano) e a Geografia da cidade (traçado e zoneamento morfológico-funcional) se revelaram fundamentais para se estudar a morfologia e as paisagens urbanas, de Congonhas, cidade ligada historicamente a Mariana, Ouro Preto, Ouro Branco, Conselheiro Lafaiete e Belo Horizonte, apresentando características semelhantes em relação ao sítio original e às atividades de exploração, no início do povoamento em Minas Gerais, cujo nascimento se deu no Ciclo do Ouro.

Do ponto de vista intraurbano, Congonhas cresce num ritmo acelerado, desordenado e em transformação, carecendo de um planejamento de controle das condições sociais e monitoramento do espaço, demonstrando precariedades na paisagem e nas dinâmicas de circulação urbana. Um aspecto que merece ser apontado diz respeito à paisagem urbana e à análise funcional e qualitativa associada a Congonhas enquanto cidade detentora de um patrimônio histórico arquitetônico e cultural significativo: os monumentos principais encontram-se ilhados em uma paisagem urbana contemporânea de escassa qualidade necessitando urgentemente de um controle urbano, tanto no âmbito do processo de criação da estrutura fundiá- 
ria, quanto no âmbito do processo de construção das novas edificações.

Do ponto de vista de relações externas, Congonhas corresponde-se à hipótese do fenômeno, de formação inicial de uma cidade difusa ${ }^{1}$, sendo afetado pelos processos de periurbanização ${ }^{2}$, sob a influência de Belo Horizonte; e a possível conurbação ${ }^{3}$, em seu espaço regional de expansão urbana, tornando-se cada vez mais independente, agregando urbanizações periféricas dispersas e heterogêneas. Porém, em virtude dessas transformações sociais e urbanas, Congonhas e as cidades limítrofes Ouro Branco e Conselheiro Lafaiete, encontramse afetadas pelo fenômeno urbano-industrial, recente, polarizado pela Açominas/Gerdau, na Bacia do Rio Maranhão.

\section{CARACTERIZAÇÃO DA CIDADE - AMBIENTE HISTÓRICO-CULTURAL CONSTRUÍDO, PERCE- BIDO, VIVIDO}

Identificada como povoado no século XVII e fundada na primeira metade do século XVIII, no ano de 1757, no ciclo do Ouro, Congonhas foi reconhecida pela UNESCO, em 03 de Dezembro de 1985, como Patrimônio Cultural da Humanidade.

Em 14 de Dezembro de 2001, a denominação "Patrimônio Cultural da Humanidade" foi alterada para "Patrimônio Cultural Mundial", também pela UNESCO. Como Cidade Histórica foi tombada pela Secretaria do Patrimônio Histórico e Artístico - SPHAN.

Por votação pública, obtendo o primeiro lugar entre as Cidades Históricas de Minas Gerais, indicadas no concurso realizado pela Rede Globo em 2004, recebeu o título de "Imagem de Minas".

\footnotetext{
${ }^{1} \mathrm{O}$ crescimento das cidades, caracterizado pelo tipo difuso reconhece três formas distintas: a periurbanização, a suburbanização e a conurbação.

2 Para Merlén (1998) e Hidalgo et al (2003a), citados por Arenas e Gonzáles (2007) a periurbanização corresponde: "la urbanización que se produce en las franjas cercanas a las grandes aglomeraciones".

3 O conceito de conurbação originou-se no século XX, por Geddes (1960), que o definiu como: "A fusão física de espaços urbanos que tem origem distinta e que é provocada pela urbanização não controlada que se difunde sobre território determinado" (HIDALGO et al., 2003a apud ARENAS; GONZÁLES, 2007, p. 500).
} 
Figura 1: Ocupação Urbana de Congonhas - Centro Original e Complexo Religioso

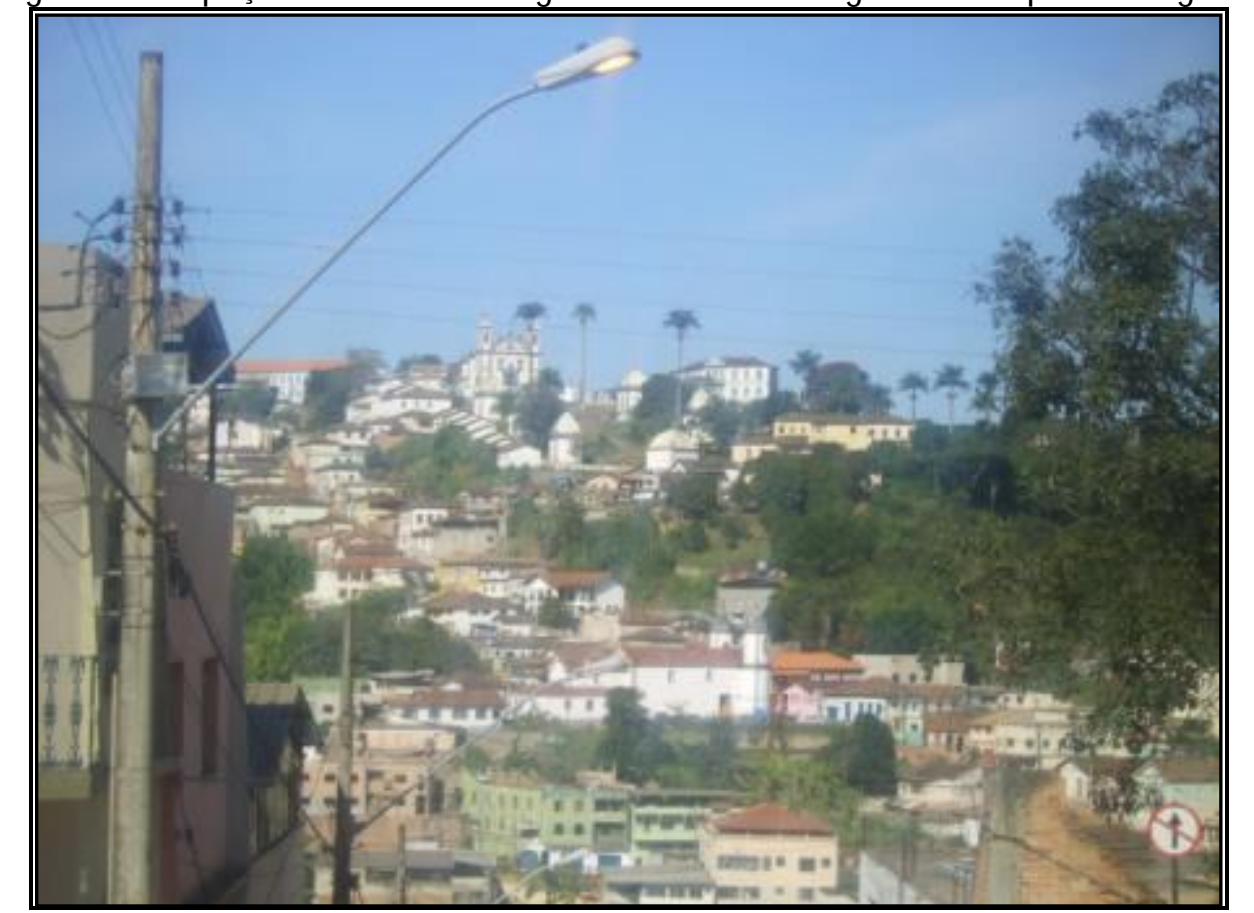

Fonte: Foto de Autoria de Mariza Ferreira da Silva, em Trabalho de Campo (2008)

Essa cidade, que rapidamente se transforma nas últimas décadas, possui um expressivo conjunto de riqueza barroca do maior artista do gênero no Brasil: Antônio Francisco Lisboa (1730), mais conhecido pelo apelido Aleijadinho. A fama do Santuário do Bom Jesus de Matosinhos não se deve apenas à questão religiosa. Ele guarda um patrimônio artístico do Brasil, representado pelas esplêndidas obras executadas pelo mestre Aleijadinho, que completam 0 caráter sacro do Santuário e a memória histórica.

No adro do Santuário do Bom Jesus de Matosinhos, Aleijadinho esculpiu em pedrasabão as famosas imagens de 12 profetas e suas profecias, sendo eles: Abdias, Amós, Baruc, Daniel, Ezequiel, Habacuc, Isaías, Jeremias, Joel, Jonas, Naum, Oséias. De acordo com os historiadores e divulgadores da Arte-M inas, além de serem inspirados pelos documentos bíblicos, os doze Profetas representados e esculpidos no adro da igreja, traduzem a expressão de sofrimento dos inconfidentes e a ideologia da Inconfidência Mineira. E Amós, é conhecido como autorretrato de Aleijadinho, por se sentir como um inconfidente que, também, aspirava liberdade.

As seis capelas que compõem o Jardim dos Passos em frente à Basílica representam a via sacra. As imagens esculpidas em cedro também são obras de Aleijadinho. São confirmadas também, as obras de Francisco Xavier Carneiro e pinturas do mestre Ataíde, inspiradas nas paisagens da região, conhecidas como "montanhas de M inas". Em Congonhas, é possível presenciar os testemunhos vivos da cultura religiosa da cidade, manifestados no modo de vida dos moradores e na reação dos turistas que procuram visitá-la, em dias de festas religiosas, consideradas como dias de Jubileu. A cidade mantém, no Santuário do Senhor Bom Jesus de Matosinhos, centenas de depoimentos, fotos e outros objetos levados por fiéis católicos para 
a Sala de Milagres e Promessas.

Destaca-se por seu movimento turístico-religioso, que pode ser concebido como um fenômeno de migração religiosa que atrai multidões de várias localidades mineiras e regiões brasileiras. Nota-se, também, a presença de turistas de várias partes do mundo. De marcante presença histórica, religiosa e turística, Congonhas é ponto de encontro de turistas e fiéis, principalmente católicos.

A pedra-sabão esculpida e o ouro das igrejas centenárias também marcam o tempo da história da cidade, incluindo-a na rede turística das cidades históricas mais visitadas de Minas Gerais. Sua origem está no período colonial para extração de ouro às margens do Rio Maranhão que faz parte da sub-bacia do Rio Paraopeba e esta, da Bacia do Rio São Francisco. Os mineiros a qualificam popularmente de cidade histórica, religiosa ou dos milagres, cidade dos Profetas e, ainda, turística ou cidade colonial.

\subsection{0 espaço regional de expansão urbana de Congonhas: a bacia do rio Maranhão}

Na figura, a seguir, observam-se os limites municipais, a localização dos municípios limítrofes de Congonhas, as sedes representadas nas manchas urbanas, os distritos de Alto Maranhão (9,0 km, do distrito da sede) e distrito de Lobo Leite $(12,0 \mathrm{~km})$, na zona periurbana de Congonhas.

As demais localidades (povoados ou assentamentos urbanos) permitem visualizar a proximidade geográfica de Congonhas e suas urbanizações, em relação à Ouro Branco e Conselheiro Lafaiete, podendo-se afirmar que há uma possibilidade de integração física a originar um processo de conurbação associada, entre esses municípios.

É possível verificar, a posição estratégica da Açominas/Gerdau, em relação aos três municípios e em relação à rede hidrográfica do Rio Paraopeba, Sub-bacia do Rio São Francisco, que tem como subafluente, o Rio Maranhão e sua micro-bacia, onde está localizada a sede de Congonhas.

A Açominas ocupa a área central desse espaço geográfico em expansão urbana, com a extração mineral e diversificadas atividades decorrentes da mineração. Observa-se, ainda, a localização da Represa da Soledade.

Em campo, é possível verificar outras represas e barragens provenientes dos rejeitos de mineração, nesse espaço regional. 
Figura 2: Bacia Hidrográfica do Rio M aranhão

\section{Bacia Hidrográfica do Rio Maranhão}

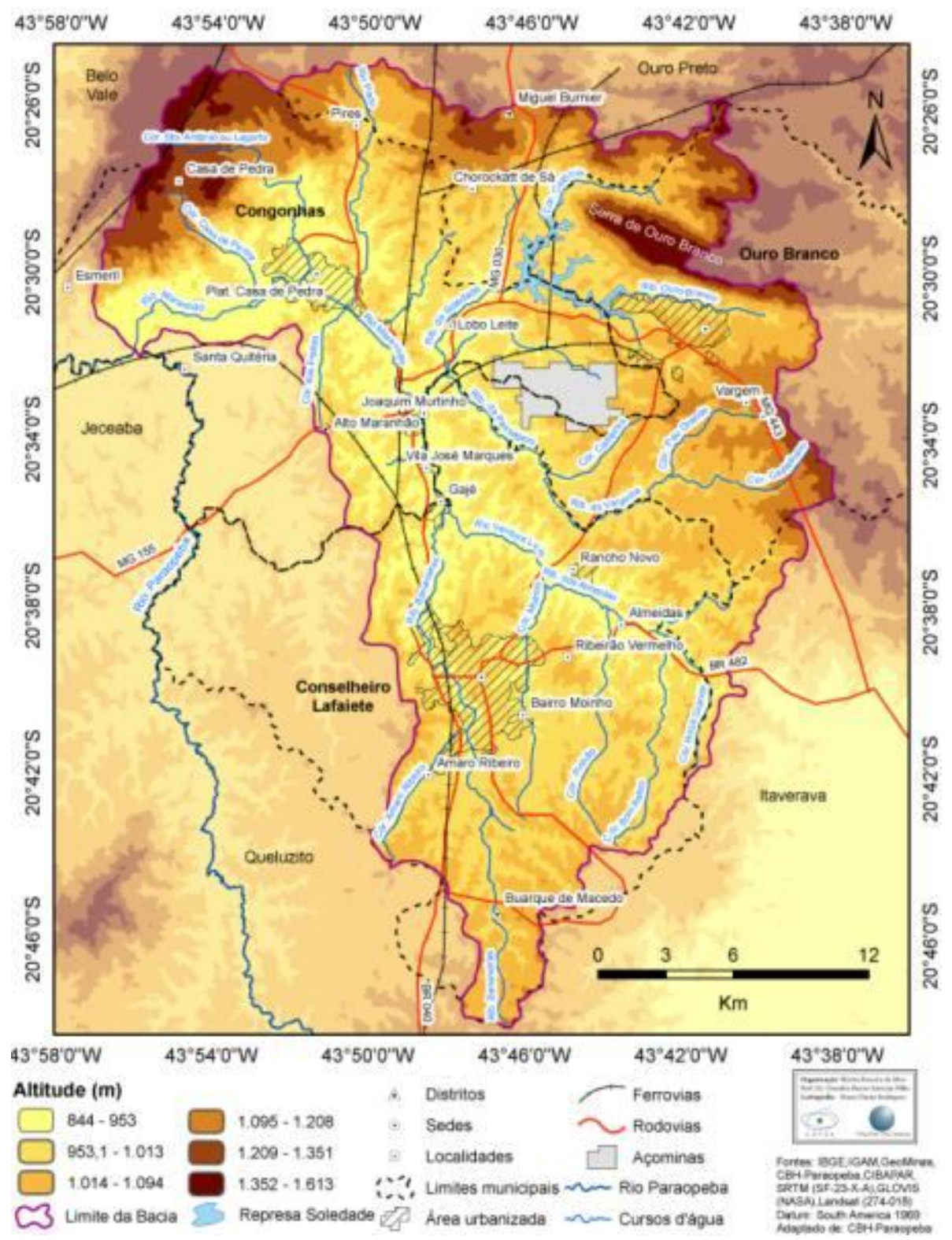

Fonte: IBGE, IGAM Fonte: Instituto Brasileiro de Geografia e Estatística, Instituto Mineiro de Gestão das Águas. Organização: Mariza Ferreira da Silva e Prof. Dr. Oswaldo Bueno Amorim Filho. Cartografia: Bruno Durão Rodrigues

Esse espaço geográfico pode ser identificado como uma área formada de "cinturões ou cinturas do minério", tendo em vista as vias concêntricas que se estabeleceram e se consolidaram nos arredores dos centros urbanos, nas novas urbanizações que surgiram para formação de mão de obra, nas cidades mineradoras e nas minas exploradoras. 


\section{METODOLOGIA DE ANÁLISE CIENTÍFICA E GEOCARTOGRAFIA APLICADA}

Como metodologia de análise, para verificar a situação urbana e o perfil funcional atual, assim como a evolução da cidade no processo de ocupação, o modelo geocartográfico de Amorim Filho (2005) intitulado "as grandes divisões morfológico-funcionais de uma cidade de porte médio", foi utilizado. Esse modelo, baseado no critério de zoneamento morfológicofiuncional pode ser, segundo seu autor, um critério que identifique o dinamismo espacial. Tornou-se adequado na análise funcional da cidade de Congonhas, servindo de apoio teórico e metodológico, durante os trabalhos de campo.

A abordagem metodológica utilizada no estudo de Congonhas permitiu investigar, de forma detalhada, a unidade urbana, o fenômeno de expansão urbano-industrial, gerando produtos cartográficos em ambientes SIGs - Sistemas de Informações Geográficas.

0 trabalho realizado tratou-se de um estudo:

a) de geografia urbana e regional, aliadas às geociências concebidas como referências de investigações integradas ao escopo do meio ambiente, a partir dos métodos de análise de sistemas de informações geográficas (SIGs), para a modelagem de sistemas ambientais ${ }^{4}$ e de concepções de planejamento ambiental ${ }^{5}$ na gestão territorial;

b) de uma cidade na transição entre as categorias hierárquicas pequena e média;

c) de um setor de uma zona perimetropolitana de uma cidade com valor histórico, turístico e paisagístico significativo;

d) de uma cidade com uma série de problemas, em especial ambientais, resultantes da urbanização, quanto das atividades econômicas, sobretudo da mineração.

Duas abordagens de análise foram utilizadas. A primeira, no sentido de perceber a cidade na região e nos demais espaços que a envolvem, as funções urbanas em seu espaço de influência, tipologias, hierarquias e redes urbanas no contexto regional e por constituir parte do espaço perimetropolizado por Belo Horizonte.

A segunda, no sentido de explorar o espaço interno da cidade: 0 sítio urbano, o zoneamento e o uso do solo, a estrutura morfológica e funcional, o espaço construído da cidade, a construção social dos espaços urbanos, as políticas e o desenvolvimento do planejamento urbano para sanar os principais problemas.

Em síntese a pesquisa realizada pretendeu estudar o processo de urbanização atual de Congonhas, manifestado na estrutura morfológica por meio das paisagens urbanas.

Quanto ao espaço interno da cidade os procedimentos utilizados foram para o reconhe-

\footnotetext{
${ }^{4}$ Antonio Christofoletti (2011[1999]) faz referência, como marco significativo, à coletânia de ensaios M odels in Geograhy, publicada em 1967, organizada por R. J. CHORLEY e P. HAGGET. Esse fato repercutiu recentemente, na União Geográfica Internacional que, no Congresso realizado em Haia (1996) criou a "Comissão sobre M odelagem de Sistemas Geográficos". Informa, ainda, que, trinta anos depois da publicação da obra de CHORLEY e HAGETT (1967) registra-se o lançamento da primeira revista internacional dedicada à modelagem geográfica, a intitulada Geographical and Environmental Modelling.

${ }^{5}$ Para estudos relacionados a Planejamento Ambiental, sugere-se a leitura do livro "Planejamento Ambiental: teoria e Prática", de Rozely Ferreira dos Santos (2004).
}

Planeta Amazônia: Revista Internacional de Direito Ambiental e Políticas Públicas 
cimento do sítio urbano, o zoneamento e o uso do solo, a estrutura morfológica e funcional, a cidade como espaço construído e espaço percebido, fazendo-se a descrição, explicação e representação dos espaços urbanos, assim como a construção social desses espaços e suas representações simbólicas.

Os procedimentos possibilitaram ainda, o conhecimento da cidade de Congonhas em sua condição atual, em suas relações externas na região e nos demais espaços que a envolvem, tendo como ponto de partida a posição geográfica, considerando os aspectos ou fatores que, direta ou indiretamente, explicam a evolução do zoneamento morfológico-funcional (cuja morfologia urbana, está representada na figura 3, desse artigo).

\section{PROBLEMAS AMBIENTAIS DA MINERAÇÃO E DA EXPANSÃO URBANA - ASSENTAM ENTOS URBANOS IRREGULARES E OCUPAÇÃO DAS ENCOSTAS COM O FATORES DE RISCO}

Em Congonhas, vê-se o pequeno núcleo urbano de sua origem, com ruelas e casarões contíguos ligados ao centro atual, mas também ligado às vilas e povoados adjacentes. De crescimento desordenado, a paisagem urbana original, caracterizada pelo complexo histórico e religioso, expande-se, formando novos núcleos de assentamento urbano, bastante significativos, nas áreas pericentrais e periféricas da cidade. De um ponto mais alto pode-se observar a morfologia de sua origem, que se funde com paisagens urbanas recentes, envolvendo 0 centro religioso e antigas áreas de mineração, as quais, junto com o tecido urbano de expansão recente formam um aglomerado urbano heterogêneo. Nota-se, ainda, o pequeno e denso espaço central, que já começa a apresentar problemas de circulação de pessoas e de mercadorias, com dificuldades para estacionamento de veículos, dificultando a passagem por esta área. Percebem-se, em alguns momentos, muitos pedestres que, ao circularem, congestionam as pequenas ruas do centro. Em dias de Jubileu a multidão é grande, ocupando, inclusive, os hotéis de cidades mais próximas. Espaços antigos preservados, revitalizados, e espaços recentes em fase de crescimento se fundem, construindo na cidade paisagens geográficas diferenciadas.

Nos últimos anos têm aumentado os problemas ambientais, principalmente inundações nas proximidades do rio M aranhão, tanto na área central, quanto nas áreas pericentral e periférica da cidade, onde estão localizados os bairros residenciais e grande parte das edificações e equipamentos de serviços públicos e particulares.

A topografia interferiu no crescimento urbano de forma desordenada, originando as ocupações de encostas e os assentamentos irregulares. Dadas às condições topográficas, os riscos naturais e urbanos são inevitáveis, a exemplo de problemas de enchentes e poluição no centro da cidade, problemas de circulação interna e de acesso ao município caracterizado por um relevo montanhoso com riscos de acidentes violentos.

A topografia da cidade pode ser considerada como um dos fatores de impedimento dos crescimentos horizontal e vertical da cidade e da impossibilidade da abertura de vias de acesso nas zonas central e pericentral, de densidade populacional alta. Essa condição prejudica, em parte, os planejamentos de redimensionamento do espaço urbano. 
Além das condições topográficas, os solos, desfavoráveis por causa das atividades de mineração que ainda ocorrem na região, tornam ainda mais difícil à execução de obras de reconstrução e ampliação de vias, a abertura de ruas e avenidas mais largas, pavimentação e planejamento arquitetônico da cidade, com infraestrutura urbanística adequada às necessidades atuais da população local e regional. Essas obras possibilitariam melhores condições de tráfego: circulação de veículos e mercadorias, mobilidade da população, reorientação dos fluxos e a melhor integração funcional no espaço de relações externas.

Apesar das dificuldades apresentadas e das condições naturais do sítio, Congonhas cresceu de forma abrupta nas três últimas décadas: tanto do ponto de vista espacial quanto do ponto de vista demográfico e funcional. Pela análise da população nos segmentos urbano e rural ficou evidente 0 acentuado processo de urbanização de Congonhas durante as últimas décadas.

0 relevo de colinas associado a alinhamentos de cristas propicia o dissecamento do terreno, tendo em vista a rede de drenagem densa, na área urbana representada pela bacia hidrográfica do Rio Maranhão, com seus inúmeros afluentes (Santo Antônio, Casa de Pedra, Macaquinhos, Gurita e ribeirão Soledade).

A área apresenta inúmeros processos erosivos, sobretudo através do voçorocamento e em lençol. Com processos erosivos, das rochas com ocorrências ferríferas e quartzíticas, resultam solos arenosos, pouco férteis e com elevado teor de acidez. Apesar das características desfavoráveis do ponto de vista topográfico, para o assentamento urbano e seu desenvolvimento, nessa área se instala o principal núcleo urbano do município, representado pela sede e pelo eixo BR-040.

Nas palavras de Rivera:

"Congonhas fica num vale, entre duas fieiras de montanhas. De um lado, o Santuário, o Hotel, os Passos e os Profetas. Do outro, a cidade anônima, com seu casario irregular. A terra é vermelha, às vezes. Mas, geralmente escura. É o minério. Pisam-se escamas de ferro, esmeris, sorvendo poeira de ferro. É zona metalúrgica, e há muitas empresas, explorando minério nos arredores. É pedra negra e mais pedra. Os Profetas, entretanto, resistem à ferrugem do tempo e às maquinarias do Século. São de pedra-sabão. E trabalhados pelas mãos informes de um gênio. 0 maior gênio barroco do mundo: Antônio Francisco Lisboa, o Aleijadinho." (RIVERA, 2002, p. 61)

Rivera expressa muito bem a sua percepção sobre o lugar chamado Congonhas. Mas Congonhas é também um espaço urbano que apresenta vários problemas, tendo em vista 0 grande número de assentamentos urbanos irregulares, próximos ao Rio Maranhão, ou nas encostas, com atividades mineradoras em áreas urbanas. Por isso, seu meio natural e urbano já se encontra bastante degradado e a cidade é considerada como área prioritária para conservação: pela fragilidade do solo, pela necessidade de proteção de mananciais (Rio Paraopeba), enfim, pelo seu valor cênico ou paisagístico.

A paisagem urbana de Congonhas a esse respeito merece uma análise específica, mas seu bem mais valioso transcende a obra arquitetônica. Para as empresas mineradoras as jazidas minerais. Para a população, a qualidade de vida humana e urbana e, ainda, as boas condi-

Planeta Amazônia: Revista Internacional de Direito Ambiental e Políticas Públicas 
ções de emprego a serem ofertadas por essas empresas. Felizmente, a Prefeitura de Congonhas - por meio de suas Secretarias M unicipais - aciona as leis que visam à preservação de seu patrimônio cultural e arquitetônico, mas também de seu patrimônio ambiental e humano. Congonhas é detentora, também, de acervos arqueológico, paleontológico e espeleológico.

\subsection{Desafios impostos pela mineração em perímetro urbano: gestão municipal participati- va, desenvolvimento ambiental sustentável, educação ecológica e erradicação de proble- mas na saúde pública}

O Jornal Estado de Minas (2011) apresentou notícias relacionadas aos "problemas decorrentes da indústria de cifras bilionárias da mineração", como desafios para a cidade que se encontra em reestruturação urbana, "pagando preços altos por estar localizada em um sítio natural de riqueza decorrente do minério de ferro de alto teor, cuja riqueza é explorada e exportada para outros países, inclusive a China". A área urbana de Congonhas tem sofrido com 0 acúmulo de lama e poeira, deixando as ruas sujas, tendo em vista o tráfego de veículos das empresas mineradoras e prestadoras de serviço, o que leva a Prefeitura a tomar atitudes de fiscalização intensa, multando as empresas e até mesmo, chegando à cassação do alvará, como informou o respectivo jornal.

De acordo com o Caderno Economia do Jornal Estado de M inas (2011), "Diariamente são retirados de 5 a 7 toneladas de pó e lama de minério das ruas e mais de 120 toneladas de pó de minério da cidade, por mês". É muita poeira, como é noticiado, "que encarde as casas, ruas, carros e paira na atmosfera, trazendo prejuízos à saúde da população, aumentando os problemas respiratórios e comprometendo o ambiente em geral". A "Guerra Contra a Poeira", segundo Anderson Costa Cabido, Prefeito da cidade, é amparada na nova Lei Ambiental sancionada em Julho de 2011, no Código Nacional de Trânsito. Para ter uma ideia, "o M inistério Público Estadual fechou cerco às empresas que ameaçavam o Patrimônio Histórico e Cultural de M inas Gerais e até Julho de 2011, já listavam 20 (vinte) procedimentos abertos contra elas", como explicou Vieira (2011), ao informar também, que, "os movimentos populares, organizados pela sociedade civil, também agiam contra as operações das atividades e expansão das minas nos perímetros urbanos".

Advertiu, ainda, que, a situação "tenderia a piorar por causa da elevação da demanda pelo minério no mercado global, o que aumentaria o desejo, de exploração em grande escala, por parte das empresas de capital nacional e internacional no segmento". Porém, para enfrentar os problemas ambientais decorrentes da mineração e, com o objetivo de traçar um modelo de desenvolvimento econômico para privilegiar a qualidade de vida, o patrimônio paisagístico e a identidade mineira da cidade histórica e mineradora, o município atua em sintonia com o Instituto de Patrimônio Histórico e Artístico Nacional, mantendo integrados os serviços das Secretarias M unicipais de M eio Ambiente, Patrimônio e Desenvolvimento Urbano, além do Conselho Municipal de Patrimônio. 0 município atua, também, em sintonia com o Ministério Público do Estado, que adota medidas de reforço na avaliação dos riscos da ati- 
vidade para a preservação do Patrimônio Histórico e Cultural dos municípios mineiros que abrigam jazidas.

Nesse sentido, como salientou Vieira (2011), no Caderno Economia do Jornal Estado de Minas, a Promotoria Estadual de Defesa do Patrimônio Cultural e Turístico de Minas, também, decidiu apertar a cobrança sobre os órgãos responsáveis pelo licenciamento ambiental de projetos de abertura e expansão de minas.

Foi no espaço geográfico, de ocorrência abundante de jazidas minerais, um meio físico acidentado, com operações intensas de mineradoras e em uma trajetória de crescimento urbano-industrial, que o tecido urbano de Congonhas, teve de se adaptar. Mas, também, no vale do principal rio que passa pela cidade, pois a sede da cidade de Congonhas, originária do povoado no período colonial, localiza-se no centro da área municipal, ocupando o vale do Rio Maranhão. Situada entre as altitudes de 869 m (Estação Ferroviária) e cerca de 1300 m (Torre de Rádio) também enfrenta dificuldades ambientais de causas naturais. Em períodos de chuvas intensas, principalmente no verão, os moradores sofrem com as tragédias causadas por enchentes, agravando ainda mais os problemas urbanos. Na área urbana ${ }^{6}$ estão localizadas duas microbacias hidrográficas: Bacia do Rio Maranhão e Bacia do Rio Santo Antônio.

Os problemas de densidade populacional, assim como os problemas sociais existentes na cidade, demonstram que, o processo de aceleração urbana de Congonhas ocorreu de forma abrupta. Indica de forma urgente, a intervenção de um planejamento de gestão urbana que redirecione o desenvolvimento ambiental sustentável, de forma equilibrada.

\section{ZONEAMENTO MORFOLÓGICO-FUNCIONAL DA CIDADE DE CONGONHAS - EXPANSÃO URBANA E HIPÓTESE DE CONURBAÇÃO COM AS CIDADES OURO BRANCO E CONSELHEIRO LAFAIETE}

Trata-se, aqui, da caracterização da morfologia e da estrutura funcional do espaço intraurbano de Congonhas. Para tentar compreender a estrutura urbana e as feições morfológicas associadas ao zoneamento funcional de Congonhas, a observação do cartograma exploratório (Figura 3) é fundamental, pois permite a análise do espaço intraurbano subdividido em quatro grandes áreas diferenciadas, bem semelhantes à descrição do modelo teórico geocartográfico de Amorim Filho (2005), aplicado a esta realidade urbana. As divisões morfológico-funcionais de Congonhas foram representadas no cartograma exploratório:

\footnotetext{
${ }^{6}$ Considera-se área urbana aquela contida em um perímetro e definida por grande concentração de ruas com infraestrutura, áreas (lotes) para assentamento da população, locais de trabalho e de compras, dotada de equipamentos no atendimento à educação, saúde, lazer e cultura, assim como de serviços de transporte coletivo, coleta de lixo, correio, telefone, água encanada, esgoto e energia elétrica, criando, dessa forma, condições de vida e relacionamento social, adequados.
} 
Figura 3: Zoneamento M orfológico-Funcional de Congonhas - M G/2011

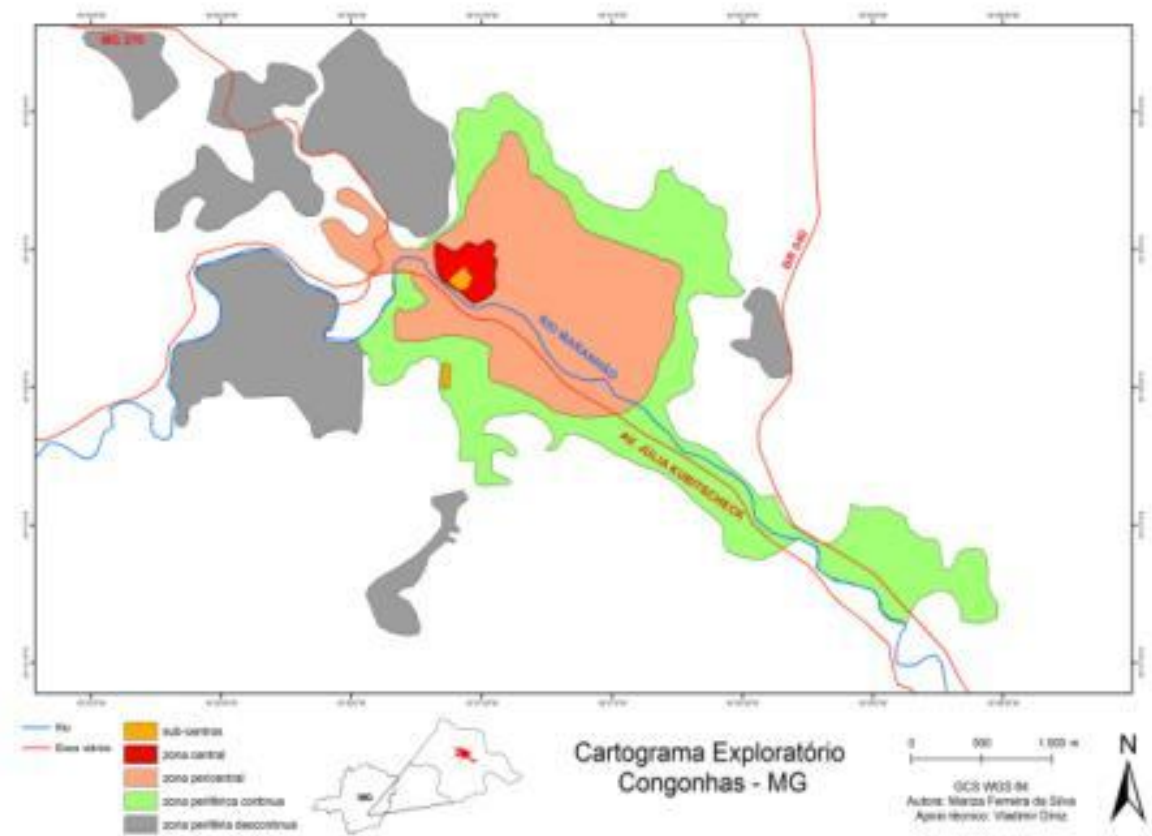

Fonte: Autoria de Mariza Ferreira da Silva e Apoio Técnico de Vladimir Diniz/Aplicação do Modelo Geocartográfico de Amorim Filho (2005)

Destaca-se aqui, que, ao observar e analisar a morfologia da mancha urbana de Congonhas verifica-se a sua expansão territorial de forma linear, no sentido sudeste, em direção a Ouro Branco e Conselheiro Lafaiete, nas proximidades da Açominas, como foi observado também, na figura 2.

Uma análise, mais detalhada, parte da observação das bordas representadas, localizadas ao entorno da mancha urbana mais compacta de Congonhas, nas periferias descontínuas e nas extremidades opostas: de Noroeste a Sudeste.

Essas bordas de urbanização difusa se encontram mais próximas dos limites municipais, podendo ultrapassá-los, compartilhando espaços de municípios vizinhos.

Ao observar as manchas urbanas representadas no cartograma exploratório, para além do centro, nota-se a diferenciação brusca das formas ou fisionomias: uma área mais compacta, constituída nas três grandes zonas (central, pericentral e periférica contínua) e as extremidades, de natureza mais dispersa ou difusa, com urbanizações mais isoladas e cada vez mais distantes do centro e da área pericentral, constituindo a zona periférica descontínua e fundindo-se à zona periurbana, tornando-se mais difícil de delimitar.

Pode-se dizer que, essas diferenciações geográficas, são também diferenciações históricas. Constatou-se no trabalho de campo que, as urbanizações difusas são mais recentes que 0 adensamento urbano do eixo central ao periférico. Essas urbanizações, que demonstram descontinuidades, são indicativas de uma dinâmica urbana mais recente do processo de urbanização de Congonhas e são percebidas como formas fragmentadas no contexto global da mancha urbana, na representação cartográfica (figura 3).

Um aspecto importante a destacar, da área representada no cartograma e no cotidia-

Planeta Amazônia: Revista Internacional de Direito Ambiental e Políticas Públicas 
no da cidade, é que essas urbanizações (mais dispersas e mais distantes da zona central) estão localizadas em áreas mineradoras e mais próximas dos municípios que compõem o Colar Metropolitano de Belo Horizonte: Belo Vale e Moeda; e a Sudoeste: Jeceaba. Todos, municípios limítrofes de Congonhas. É, exatamente nesse contexto geográfico, que há uma previsão de construção de duas barragens de rejeitos no município de Jeceaba integrando o Projeto da Ferrous, em Congonhas, para a produção de 15 milhões de toneladas de minério de ferro ao ano, de acordo com informações extraídas no Jornal Estado de M inas (2010). Em Congonhas, nas imediações dessas áreas de urbanização mais difusa, a "CSN - Companhia Siderúrgica Nacional, única entre as grandes, a ter capital exclusivamente brasileiro, vai investir bilhões na ampliação da produção da Mina Casa de Pedra, na instalação de uma unidade de transformação do minério de ferro em pelotas de minério (pelotização) e na construção de uma nova usina siderúrgica", segundo Estado de M inas (2010). Em 2009, a população estimada da cidade era de 48 mil habitantes, mas a expectativa é que esse número dobraria de volume, nos próximos cinco anos em razão destes investimentos anunciados, de acordo com o Jornal. Em 2014, em entrevista com o Secretário de Desenvolvimento Sustentável, foi apresentado um dado de que "os habitantes flutuantes do município - trabalhadores das mineradoras, que se deslocam de cidades vizinhas, somavam cerca de 20 mil pessoas" (COSTA, 2014).

Outro aspecto ressaltado no artigo "As Serras Peladas de M inas" do Caderno Economia, do mesmo Jornal no ano de 2010 é que, entre 6 horas e 7 horas da manhã, um dos efeitos danosos do aumento populacional começa a se fazer sentir na cidade. "Nesse horário é impossível trafegar na Avenida Júlia Kubitscheck (a principal de Congonhas). Às 18 horas, quem chega, gasta uma hora para percorrer um trecho de dois quilômetros, que vai do trevo ao centro", informa Gualter M onteiro, proprietário da imobiliária Imgel e Ex-Prefeito da cidade por três mandatos, ao conceder entrevista para o Jornal.

Nas extremidades opostas, no sentido Sudoeste e Noroeste em direção a M G 270, e no sentido Sudeste em direção a BR 040, as urbanizações periféricas e descontínuas são de natureza polinuclear. Esses pequenos núcleos, podendo ser denominados de subcentros polifuncionais e em alguns casos especializados, representam povoados e vilas regulares ou não, na periferia descontínua de Congonhas, mais distantes do centro e cada vez mais próximos dos municípios vizinhos. Nessa área do município, na zona periférica descontínua (Noroeste/Sudoeste) da cidade, verifica-se a influência da Companhia Siderúrgica Nacional. Entretanto, na zona periférica descontínua (Sudeste) em direção à BR 040, a influência principal é da Açominas.

No cartograma (Figura 3), é possível perceber dois processos de evolução urbana, distintos:

- o primeiro, a urbanização tradicional linear, que progrediu do centro para a periferia contínua, como mancha de óleo, seguindo os principais eixos viários em direção a BR 040, rodovia de grande importância econômica, construída para ligar Belo Horizonte ao Rio de Janeiro, passando pelas imediações de Congonhas, Ouro Branco e Conselheiro Lafaiete. A continuidade da mancha urbana de Congonhas nesse trecho evidencia o crescimento urbano que margeia o Rio Maranhão e a principal avenida da cidade de Congonhas, a Av. Júlia Kubits- 
check, estendendo-se para além desses domínios e ultrapassando a BR 040. É exatamente nesse trecho que se pode perceber o processo inicial de conurbação que ligará o tecido urbano de Congonhas às cidades de Conselheiro Lafaiete e Ouro Branco. É comandado pela sede microrregional. Na região de possível conurbação, a influência da Açominas é evidente, assim como a RMVA - Região Metropolitana do Vale do Aço, na porção Leste - Sudeste do Colar Perimetropolitano;

- o segundo processo de urbanização é identificado como a formação de uma periferia descontínua, polinuclear e de feição difusa, na direção oposta à BR 040 e mais próxima dos municípios limítrofes de Congonhas e pertencentes ao Colar M etropolitano da Região M etropolitana de Belo Horizonte. Os municípios pertencentes a esta porção regional têm relação mais direta com Belo Horizonte, RM BH e possivelmente com Congonhas. Provavelmente apresentam relações menos intensas com Conselheiro Lafaiete. Esse processo de urbanização polinuclear e de agregação nas periferias de Congonhas aponta para o processo de periurbanização. É possível sugerir o processo inicial de uma cidade difusa.

\section{CONSIDERAÇÕES FINAIS}

Constatou-se, em atividades de campo e com o auxílio da metodologia que originou 0 produto cartográfico de representação da estrutura morfológico-funcional, que a cidade de Congonhas constitui-se de, uma zona central, cujo núcleo principal é marcado pela predominância de funções terciárias; uma zona pericentral extensa espacialmente e de predominância residencial, de natureza polifuncional, duas zonas periféricas e uma zona periurbana, de transição urbano-rural.

Na zona central, a função terciária é predominante, onde se localiza a sede ou distrito principal do município na principal avenida da cidade, eixo viário que liga o centro às demais áreas intraurbana e à BR 040 em direção a Belo Horizonte, a Conselheiro Lafaiete ou ao Rio de Janeiro. A mesma avenida que passa pelo centro liga-o a M G 270.

As zonas pericentral e periférica contínua apresentam-se como um prolongamento da zona central. 0 centro principal se diferencia desde a sua origem, das demais partes da cidade, tanto pela presença do espaço público de que se dispõe, quanto das funções exercidas por ele, no âmbito da administração pública municipal e da oferta de serviços, por meio dos equipamentos urbanos existentes. Demonstra uma diferenciação interna com paisagem e morfologia típicas de um centro que possui uma maior densidade de construções, movimento de veículos e pessoas, em comparação às outras áreas da cidade. A função residencial já se encontra bastante superada pelas funções terciárias. Nas imediações do subcentro comercial de Congonhas, no limiar da zona pericentral em direção à periferia contínua, encontram-se unidades desorganizadas e algumas vilas precárias e de constituição frágil em áreas bem próximas do leito do rio.

A Zona Pericentral, extensa espacialmente, de função residencial predominante ao longo dos eixos viários, praças e entroncamentos, caracterizada por diferenças socioeconômicas, encontra-se no espaço de transição entre a zona central e a zona periférica contínua. 
Essa área se confunde com as áreas periféricas, no caso específico de Congonhas, em virtude da topografia da cidade, tendo em vista que a urbanização se expandiu do vale para as encostas, atingindo o topo dos morros.

A Zona Periférica, morfologicamente assume duas formas: a periferia contínua, ou "mancha de óleo" e a periferia descontínua, ou "polinuclear", de crescimento identificado como "saltos". No crescimento da periferia descontínua ou polinuclear, duas unidades morfológicas aparecem em destaque: os bairros resultantes de loteamentos e as unidades mal organizadas, denominadas localmente vilas. A ocupação urbana de tipo loteamento encontrase na área de transição: pericentral para periférica contínua (como prolongamento da zona pericentral) e entre as periferias contínua e descontínua. A diferenciação morfológica e paisagística é em função de diferenças socioeconômicas, mas também naturais (topológicas: declividades). A zona geográfica denominada de periferia descontínua apresenta "vazios urbanos" em alguns pontos das vertentes e ocupações urbanas de encosta, ao longo do eixo rodoviário caracterizando unidades mal integradas.

A Zona Periurbana de Congonhas, de transição urbano-rural mais ou menos extensa, e suas imediações ainda de vegetação densa, conta com equipamentos de natureza industrial, tendo em vista a ação das mineradoras no entorno da cidade. Em suas matas são encontradas centenas de espécies de árvores, algumas em extinção, como o jacarandá, o cedro, a mescla, a quaresmeira, além de aves como a maritaca, inúmeras espécies de bem-te-vis, pintassilgos, a lontra (que habita os córregos e rios da região), a paca e o tatu-bandeira. Dezenas de nascentes de água potável, também, são encontradas. Essa zona se funde com o perímetro urbano de outras cidades.

Problemas de natureza socioeconômica apresentam-se como desafios para os administradores locais. Há vários assentamentos ao longo de ferrovias e rodovias na região de Congonhas em direção às cidades de Ouro Branco e Conselheiro Lafaiete. Essa condição atual de Congonhas, que a faz manter relações externas intensas com municípios vizinhos carece de políticas de urbanização e de segurança para a população. São imprescindíveis, tendo em vista as desigualdades econômicas e as disparidades sociais, às vezes reforçadas pelos crescimentos econômico e demográfico que vêm se acelerando, ultimamente.

Considerando a estrutura espacial urbana como a diferenciação intraurbana resultante do processo de transformação da cidade, onde interferem fatores tais como os aspectos funcionais, econômicos e sociais é que se verificou o rápido crescimento urbano de Congonhas e 0 consequente surgimento de novas periferias.

\section{REFERÊNCIAS}

AM ORIM FILHO, Oswaldo Bueno. A Morfologia das Cidades Médias. Goiânia: Vieira, 2005. CHRISTOFOLETTI, Antonio. Modelagem de Sistemas Ambientais. São Paulo: Blucher, 1999. FURBINO, Z. As Serras Peladas de M inas. Estado de Minas, Belo Horizonte, 25 abr. 2010. Economia, p. 15.

FURBINO, Z. Desafio Econômico: Exploração na Mira Da Justiça. Estado de Minas, Belo Hori- 
zonte, 25 abr. 2010. Economia, p. 17.

M INERAÇÃO e Ambiente. Opinião, 16 jul. 2011. Editorial, p. 8.

RIVERA, B. Roteiro de Minas: v. 232. Belo Horizonte: Itatiaia, 2002.

SANTOS, Rozely Ferreira Dos. Planejamento Ambiental: teoria e Prática. São Paulo: Oficina de Textos, 2004.

SILVA, Mariza Ferreira Da. Congonhas: Centro Urbano Emergente no Colar Perimetropolitano de Belo Horizonte - MG. Dissertação de Mestrado. Programa de Pós-Graduação em Geografia - Tratamento da Informação Espacial. Pontifícia Universidade Católica de M inas Gerais. Belo Horizonte, 2011.

SILVA, Mariza Ferreira Da. Congonhas: Centro Urbano Emergente no Colar Perimetropolitano de Belo Horizonte - MG. São Paulo: All Print. 1ạ Edição. 2014.

TAKAHASHI, P., RIBEIRO, Luiz. Cidades M édias de M inas Avançam a Passos Largos. Estado de Minas, 14 jul. 2011. Economia, p. 16.

TAKAHASHI, P. et al. M unicípios com Economia Mais Diversificada. Estado de Minas, Belo Horizonte, 14 jul. 2011. Economia, p.17.

TAKAHASHI, P. Municípios Que Eram Conhecidos Como Dormitórios, na Grande BH, Começam a Virar o Jogo: Vizinhas Acordam Para Negócios. Estado de Minas, Belo Horizonte, 14 jul. 2011. Economia, p. 18.

A TRISTE Sina das Cidades Encardidas. Estado de Minas, 25 abr. 2010. Manchete.

VIEIRA, M. Desafio Econômico: Compensação Apenas Simbólica. Estado de Minas, Belo Horizonte, 25 abr. 2010. Economia, p. 17

VIEIRA, M. Exploração Mineral: Pedra No Caminho das Mineradoras. Estado de Minas, Belo Horizonte, 16 jul. 2011. Economia, p. 11

Artigo recebido em 26 de agosto de 2016.

Aprovado em 31 de dezembro de 2016. 